\title{
Endocrine and pubertal disturbances in optic nerve hypoplasia, from infancy to adolescence
}

\author{
Oliver J Oatman ${ }^{1 *}$, Donald R McClellan ${ }^{1}$, Micah L Olson ${ }^{1}$ and Pamela Garcia-Filion ${ }^{1,2}$
}

\begin{abstract}
Background: Endocrinologic abnormalities are a common co-morbidity in patients with optic nerve hypoplasia $(\mathrm{ONH})$, however the impact on puberty is unknown. The purpose of this study was to examine rates of endocrine dysfunction and pubertal disturbances in a pediatric population of $\mathrm{ONH}$.

Methods: A retrospective chart review was conducted on a cohort of children with ONH between January 2005 and March 2013. Endocrine dysfunction was determined based on laboratory evidence of hormone deficiency or hormone replacement. Pubertal disturbances were characterized based on presence of micropenis, tanner staging, menarche and hormone replacement. Pituitary abnormalities were classified using MRI findings. Descriptive statistics were used, and comparisons between groups were performed using the chi-square test.

Results: During the study period, 101 patients underwent an endocrine evaluation (median age: 2.3 years [0.76 - 6.5]). Hypopituitarism was present in $73 \%$ of patients with growth hormone deficiency (56\%) and hypothyroidism (54\%) being the most common. Pubertal disturbances $(n=19)$ were common; micropenis in 31\% (13/42) of males and $2 \%$ with precocious puberty. Half of adolescents $(n=4 / 8)$ were diagnosed with gonadotropin deficiency. Patients with MRI pituitary abnormalities were more likely to have endocrine dysfunction than those without $(p=0.004)$. The sensitivity and specificity of MRI pituitary abnormalities for hypopituitarism was $54 \%$ and $92 \%$, respectively.

Conclusions: A significant proportion of children with ONH have endocrine dysfunction. The high frequency of pubertal disturbances in this study emphasizes the need for long-term monitoring of developing endocrinopathy. While pituitary gland abnormalities are a good predictor of endocrine dysfunction, a normal pituitary gland does not rule out endocrinopathy.
\end{abstract}

Keywords: Optic nerve hypoplasia, Septo-optic dysplasia, Panhypopituitarism, Hypopituitarism, Puberty

\section{Introduction}

Optic nerve hypoplasia $(\mathrm{ONH})$ is a congenital malformation that manifests as a spectrum disorder of visual impairment with cerebral malformations, hypopituitarism and developmental delay [1-3]. The prevalence of $\mathrm{ONH}$ is estimated at 1.73 per 10,000 children [4]. In the United States, ONH is a leading cause of legal blindness in children age 3 years or younger [5].

One of the most widely studied and recognized clinical association of $\mathrm{ONH}$ is hypopituitarism, ranging from $6 \%$ to $82 \%$ depending on the study design and patient sampling [6-13]. In a prospective clinical registry of young children with $\mathrm{ONH}$, endocrinopathy affected $60-79 \%$ of

\footnotetext{
* Correspondence: ooatman@phoenixchildrens.com

'Division of Pediatric Endocrinology and Diabetes, Phoenix Children's

Hospital, 1919 E. Thomas Road, Phoenix, AZ 85016, USA

Full list of author information is available at the end of the article
}

children by age five years [10-12]. The most common hormone deficiency is growth hormone $(\mathrm{GH})$ followed by central hypothyroidism $[9,11]$. Clinical management guidelines recommend long-term follow-up given reports of evolving central hypothyroidism [14], subclinical GH deficiency (paradoxical "growth without GH") [10], and the association of untreated hypopituitarism with developmental delay and even death [12-15].

Pubertal disturbances are an understudied endocrinopathy in children with $\mathrm{ONH}$. There have been more than a dozen cases of precocious puberty and/or gonadotropin deficiency reported [16-18] implicating pubertal disturbances as an additional risk. The unknown prevalence is likely due to past research being limited to prepubertal cases and absence of long-term follow-up into adolescence.

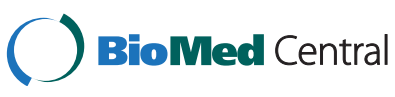

(c) 2015 Oatman et al.; licensee BioMed Central. This is an Open Access article distributed under the terms of the Creative Commons Attribution License (http://creativecommons.org/licenses/by/4.0), which permits unrestricted use, distribution, and reproduction in any medium, provided the original work is properly credited. The Creative Commons Public Domain Dedication waiver (http://creativecommons.org/publicdomain/zero/1.0/) applies to the data made available in this article unless otherwise stated. 
The purpose of this study was to retrospectively examine the prevalence of hypopituitarism in a clinical cohort of patients with $\mathrm{ONH}$ age 18 years and younger. The results of this study provide additional evidence of endocrinopathy risk throughout the age continuum in children with $\mathrm{ONH}$.

\section{Methods}

A retrospective study of patients with $\mathrm{ONH}$ was conducted on all patients evaluated in an endocrinology clinic at Phoenix Children's Hospital between January 2005 and March 2013. All patients with a documented diagnosis of $\mathrm{ONH}$ or septo-optic dysplasia were included. Data abstracted from the medical record included patient demographics, anthropometric measures (height, weight, weight for length, body mass index), hormone test results, medications, and neuroradiographic findings from magnetic resonance imaging (MRI). Self-identified race was obtained based on medical record documentation with the following classifications: Caucasian, Hispanic, Native American, African-American, or other.

Subjects' endocrine status was determined based on laboratory evidence of a hormone deficiency or current hormone replacement prior to clinic presentation. Laboratory test results were obtained when available. Patients were classified as GH deficient (GHD) based on subnormal growth factors [insulin-like growth factor-1 (IGF-1) and insulin-like growth factor binding protein-3 (IGFBP3)] levels below reference ranges, failed GH stimulation test with peak $\mathrm{GH}$ level $<10 \mathrm{ng} / \mathrm{mL}$ (using arginine, clonidine, or glucagon as stimulation agents), or hormone replacement. Central hypothyroidism was determined based on free thyroxine (T4) levels below reference ranges or hormone replacement. Adrenal insufficiency was determined based on fasting morning cortisol below reference ranges, subnormal cortisol response to adrenocorticotropic hormone (ACTH) stimulation test (peak $<18 \mu \mathrm{g} / \mathrm{dL}$ ) or hormone replacement. Patients treated with desmopressin were classified as having diabetes insipidus.

Pubertal disturbance was ascertained based on presence of micropenis (stretched penile length 2.5 standard deviations below the mean), advanced or delayed tanner staging, premature or absence of menarche, and/or the need for testosterone or estrogen replacement. Precocious puberty was determined based on presence of secondary sexual characteristics prior to age eight in females and age nine in males with evidence of pubertal levels of gonadotropins, testosterone or estradiol, or history of treatment with a gonadotropin-releasing hormone $(\mathrm{GnRH})$ agonist. Gonadotropin deficiency was based on absence of menarche in females by age 15 or no secondary sexual characteristics by age 13 in females and 14 in males.

\section{Data analysis}

A descriptive analysis was conducted using Stata 13.0 (College Station, TX). Clinical and demographic findings were summarized using medians (interquartile range) and proportions. Comparisons between groups were performed using the chi-square test for categorical variables. Statistical significance was defined as an alpha of $<0.05$.

\section{Results}

\section{Cohort characteristics}

Data from 101 patients with $\mathrm{ONH}$ were available for review. Table 1 presents the patient characteristics for the study sample. The median age at the time of clinic presentation was 2.3 years $(0.7,6.5)$. For the overall cohort, the median height and weight $\mathrm{z}$-scores were $-1.3(-2.2,-0.3)$ and $-0.7(-1.7,-0.6)$, respectively. Among subjects less than age two years $(n=47)$, the median weight for length $z$-score was $0.6(-0.6,1.3)$. The median body mass index (BMI) z-score, measurable in those age two years or older $(n=50)$, was $0.7(-0.3,1.5)$.

\section{Endocrine evaluation}

Seventy-two percent $(n=73 / 101)$ of patients had at least one endocrinopathy (Table 1$)$ and 57\% $(\mathrm{n}=58 / 101)$ had multiple pituitary hormone deficiency (MPHD) (2 or more hormone deficiencies). Among subjects with GHD (62\%), the median height SDS was $-1.6(-2.5,-0.7)$ compared to $-0.45(-1.6,0.2)$ deemed GH sufficient $(p=0.001)$. There were three cases of isolated hypothyroidism, one case of isolated adrenal insufficiency and one case of isolated gonadotropin deficiency. All cases of diabetes insipidus $(\mathrm{n}=28)$ co-existed with another pituitary deficiency: GHD (71\%), hypothyroidism (86\%) and adrenal insufficiency (82\%).

At the initial endocrine visit [median age 2.3 years $(0.7,6.5)$ ], thyroid hormone levels were measured in $82 \%$ (TSH: $82 \%$ and free T4: 98\%), cortisol in $86 \%$, and GH surrogates (IGF-1 and/or IGFBP3) in $89 \%$. Seventy-one percent underwent serial free T4 testing after initial normal thyroid tests. Nearly all patients $(>80 \%)$ underwent follow up testing for cortisol (repeat cortisol and/or cortisol provocative testing: $86 \%$ ) and GH (repeat IGF's and/or GH stimulation test: 83\%). Pubertal hormone levels, in those younger than age 6 months or at pubertal age $(n=41)$, were measured in $42 \%$ for luteinizing hormone (LH)/ follicle-stimulating hormone (FSH) and 35\% for testosterone or estradiol.

\section{Pubertal disturbances}

There were 15 subjects with a pubertal disturbance prior to pubertal age: two with precocious puberty and 13 (out of 42 males) with micropenis. Among males with micropenis, two were followed into a pubertal age; both 
Table 1 Characteristics of ONH cohort

\begin{tabular}{|c|c|c|}
\hline & $\%$ & $\mathbf{N}$ \\
\hline \multicolumn{3}{|l|}{ Gender } \\
\hline Female & 58.4 & $59 / 101$ \\
\hline Male & 41.6 & $42 / 101$ \\
\hline \multicolumn{3}{|l|}{ Referral Source $^{a}$} \\
\hline Pediatrician & 69.3 & $70 / 101$ \\
\hline Ophthalmologist & 14.9 & $15 / 101$ \\
\hline Neurologist & 5.9 & $6 / 101$ \\
\hline Other & 5.9 & $6 / 101$ \\
\hline Self-referral & 2 & $2 / 101$ \\
\hline Unknown & 2 & 2/101 \\
\hline \multicolumn{3}{|l|}{ Race/Ethnicity ${ }^{\mathbf{b}}$} \\
\hline Caucasian & 44.6 & $45 / 101$ \\
\hline Hispanic & 24.8 & $25 / 101$ \\
\hline Native American & 12.9 & $13 / 101$ \\
\hline Other & 7 & $7 / 101$ \\
\hline Not documented & 10.9 & $11 / 101$ \\
\hline \multicolumn{3}{|l|}{ Laterality of $\mathrm{ONH}$} \\
\hline Bilateral & 74.3 & $75 / 101$ \\
\hline Unilateral & 11.9 & $12 / 101$ \\
\hline Not documented & 13.9 & $14 / 101$ \\
\hline \multicolumn{3}{|l|}{ Brain Malformations ${ }^{c}$} \\
\hline Pituitary abnormalities & 44.1 & $26 / 59$ \\
\hline Absence of septum pellucidum & 46.8 & $36 / 77$ \\
\hline Corpus callosum hypoplasia & 34.7 & $25 / 72$ \\
\hline Cortical dysplasia & 16.9 & $14 / 83$ \\
\hline Schizencephaly & 10.9 & $9 / 83$ \\
\hline Hydrocephalus & 8.4 & $7 / 83$ \\
\hline Arachnoid cyst & 6.0 & $5 / 83$ \\
\hline \multicolumn{3}{|l|}{ Endocrinopathies $^{d}$} \\
\hline Any endocrinopathy & 72.3 & 73/101 \\
\hline GH deficiency & 62.0 & $57 / 92$ \\
\hline Hypothyroidism & 54.0 & $54 / 100$ \\
\hline Adrenal insufficiency & 51.1 & $47 / 92$ \\
\hline Diabetes insipidus & 27.7 & $28 / 101$ \\
\hline
\end{tabular}

${ }^{a}$ Some insurance plans only allow the primary pediatrician to order referrals.

${ }^{b}$ Based on documentation in the medical record.

'Total number of subjects varies based on available MRI reports.

${ }^{\mathrm{d}}$ Total number of subjects varies based on available lab results.

were Tanner I at age 10 and 16 years. There was no association between presence of micropenis and MPHD $(\mathrm{p}=0.72)$.

Among subjects at a pubertal age $(n=26), 24$ had a Tanner stage evaluation. Nine females (out of 15) were Tanner II-V and six were Tanner I (age 8-9 years old). Five males (out of 9) were Tanner II-V and four were Tanner I (age 10-16 years old).
There were 15 girls at potential menarchal age ( $\geq 9$ years); $40 \%$ had spontaneous menarche (median age of onset 12 years; 10.5 - 13 years). In those with MPHD, 66\% $(\mathrm{n}=4 / 6)$ had spontaneous menarche by age 15 .

Eight patients (two males and six females) were followed into an age when gonadotropin deficiency could be assessed, with $50 \%(n=4 / 8)$ being diagnosed. One male with MPHD was diagnosed with gonadotropin deficiency based on a Tanner I stage at age 16 years with low FSH, $\mathrm{LH}$, and testosterone levels (started testosterone therapy). Three females were diagnosed with gonadotropin deficiency and all had MPHD. One female had menarche at age 14, but subsequently developed irregular periods in her late teen years; she had low estrogen and LH / FSH levels and began estrogen therapy. A second female did not achieve menarche by 15 with only Tanner II breast development and no pubic hair (started estrogen therapy). A third female failed to achieve menarche by age 15 years with Tanner II pubic hair, no breast development, and low LH/FSH levels (lost to follow-up).

\section{Brain malformations}

Eighty-two patients underwent a MRI. Table 1 lists the findings documented in the MRI report. An absent septum pellucidum, present in $47 \%$, was not associated with hypopituitarism ( $75 \%$ versus $76 \% ; \mathrm{p}=0.951)$. The pituitary gland status, documented for 59 subjects, was abnormal in 25 cases. The frequency of pituitary gland abnormalities was similar for those with (54\%) and without (63\%) the septum pellucidum $(\mathrm{p}=0.530)$. Pituitary gland abnormalities included an absent or hypoplastic pituitary gland in $(n=18)$, ectopic posterior pituitary $(n=13)$, absent or truncated stalk $(\mathrm{n}=13)$, and absent posterior pituitary bright spot $(n=4)$. An ectopic posterior pituitary gland (stalk present in nine patients) was associated with DI in three cases (stalk present in two). A non-visualized posterior pituitary bright spot was an isolated finding for three subjects (no DI), and associated with an absent stalk in one subject (no DI).

Hypopituitarism manifested in $96 \%$ of patients with a reported pituitary gland malformation, compared to $64 \%$ of those with an intact pituitary gland $(\mathrm{p}=0.004)$. The sensitivity and specificity of MRI pituitary abnormalities for hypopituitarism was $54 \%$ and $92 \%$, respectively. The predictive values were 96\% (positive) and 36\% (negative).

\section{Discussion}

The high prevalence of hypopituitarism in our cohort confirms previous reports of endocrinopathy in a majority of cases of $\mathrm{ONH}[2,9-12]$. Overall, pubertal disturbances affected one-fifth of the cohort.

Pubertal disturbances in association with $\mathrm{ONH}$ was first described in 1978 in a female with precocious puberty [16]. Since then there have been 11 reported cases of 
precocious puberty in children with $\mathrm{ONH}$ (Table 2). In the present study, precocious puberty affected two patients (2\%). The exact mechanism of precocious puberty in $\mathrm{ONH}$ is unknown. Huseman et al. [16] originally postulated that precocious puberty may be due to "decreased inhibitory inputs from higher centers of the central nervous system." Since $\mathrm{ONH}$ is a neurodevelopmental abnormality, it is reasonable to assume there could be a disruption in inhibitory inputs or an increase in excitatory inputs to the hypothalamic GnRH neurons, leading to dysregulated GnRH secretion and precocious puberty. Hydrocephalus and arachnoid cysts, cerebral developmental abnormalities known to cause precocious puberty [19], were seen in seven and five patients in this study. However, neither patient with precocious puberty had these abnormalities. Future studies should examine the association of precocious puberty with these cerebral abnormalities.

Pubertal disturbances are linked to a disruption of the hypothalamic-pituitary-gonadal (HPG) axis. Ascertainment of pubertal hormone deficiencies is complicated by the limited time periods for measurement of pubertal hormone levels. Infants undergo a 'mini-puberty' during the first six months of life. If this early window is missed, pubertal hormones cannot be measured until an age when secondary sexual characteristics may occur naturally ( $\geq 8$ in females, $\geq 9$ in males). In males, micropenis is the most commonly reported sign of pubertal disturbances in $\mathrm{ONH}$, present in one-third of males in this cohort. Since micropenis is not present in all cases of gonadotropin deficiency, future research should include follow up of male patients with $\mathrm{ONH}$ into adolescence to establish a diagnosis of gonadotropin deficiency.

Researchers posit gonadotropin deficiency is less common in patients with $\mathrm{ONH}$ and MPHD compared to other causes of MPHD, which may reflect migration of GnRH neurons from the nasal mucosa to the hypothalamus after the proposed insult in $\mathrm{ONH}[18,24]$. In $\mathrm{ONH}$, the pituitary gland is structurally intact in the majority of cases $[6,11,13]$. Formation of the anterior pituitary gland precedes development of the posterior pituitary, stalk and hypothalamus at seven weeks. Hypothalamic releasing factors are present around 10-14 weeks, with a functional hypothalamic-hypophyseal portal system by the 11th week. This complex network allows communication of hypothalamic releasing factors to their respective pituitary somatotrophs, thyrotrophs, corticotrophs, and gonadotrophs, stimulating the release of anterior pituitary hormones. Unlike other hypothalamic releasing factor neurons, GnRH neurons migrate from the olfactory placode to the hypothalamus by $10-14$ weeks $[25,26]$. It is reasonable to assume that an insult to the hypothalamic-pituitary axis prior to this time period may result in preserved GnRH function.

Gonadotropin deficiency has been reported in multiple patients with ONH (Table 2), yet a prevalence has been difficult to establish as very few patients are followed into pubertal age. Nanduri et al. [18] reported gonadotropin deficiency in $42 \%$ of children with $\mathrm{ONH}$ that reached pubertal age. Our study found gonadotropin deficiency in $50 \%$ of those at pubertal age. In other hypothalamic-pituitary diseases (without $\mathrm{ONH}$ ), gonadotropin deficiency is common: $96 \%$ in child-onset craniopharyngioma and $86 \%$ in child-onset hypopituitarism (mostly idiopathic) [27].

The lower prevalence of gonadotropin deficiency in ONH may support the theory of an intact HPG axis due to a later GnRH migration into the hypothalamus. However, if this was entirely true, then no cases of gonadotropin deficiency would be expected. A completely functional HPG axis is needed for normal pubertal development. Gonadotropin deficiency could be explained by an insult to the pituitary gland itself, resulting in abnormal gonadotroph development. Very few patients in our study of pubertal age had MRI reports available, so pituitary abnormalities could not be evaluated in relation to gonadotropin deficiency.

Expert opinion recommendations encourage a thorough and serial endocrine evaluation on all patients with $\mathrm{ONH}$ regardless of MRI findings owing to the high prevalence

Table 2 Pubertal disturbances in ONH

\begin{tabular}{lllll}
\hline Study & Sample size & Precocious puberty cases & Gonadotropin deficiency cases & Micropenis cases \\
\hline Huseman, 1978 [16] & 5 & 1 & - & - \\
Margalith, 1985[20] & 17 & 1 & 2 & - \\
Hanna, 1989 [17] & 13 & 1 & 4 & - \\
Siatkowski, 1997 [21] & 35 & 1 & - & 2 \\
Nanduri, $1999[18]$ & 25 & - & 5 & - \\
Phillips, $2001[6]$ & 67 & - & - & 3 \\
Reidl, 2002 [22] & 25 & - & 1 & - \\
Birkebaek, 2003 [7] & 55 & 6 & 2 & - \\
Haddad, 2005[9] & 56 & 1 & - & 12 \\
Mohney, 2013 [23] & 19 & 1 & - & - \\
\hline
\end{tabular}


of hypopituitarism, variability in timing of onset, and evolving hypopituitarism $[1,14]$. However, there is debate about the use of imaging findings to direct endocrinologic testing in patients with $\mathrm{ONH}$ [28]. Phillips et al. [6] and Birkebaek et al. [7] were the first to suggest selective screening for hypopituitarism in patients with pituitary gland abnormalities. In some reports, the sensitivity and specificity of pituitary abnormalities on MRI ranged from $85 \%$ to $96 \%$ and $57 \%$ to $100 \%$, respectively $[6,7,13]$. A prospective study of young children with $\mathrm{ONH}$ reported a high specificity (100\%) and a low sensitivity of $7 \%$ [10]. In our cohort, pituitary gland abnormalities on MRI had a sensitivity of $54 \%$ and specificity of $92 \%$. The low negative predictive value in the study by Ahmad et al. [10] (29\%) and our study (36\%) indicates a structurally intact pituitary gland is a poor predictor of normal endocrine function. High negative predictive values reported in other studies may reflect incomplete endocrine screening.

The HPG axis was evaluated in nearly half of our patients less than 6 months old or at pubertal age. Given our findings of a pubertal disturbance in 19\% of subjects and 50\% of pubertal patients diagnosed with gonadotropin deficiency, an evaluation of the HPG axis should be performed in all patients with $\mathrm{ONH}$.

There were several limitations in our study. Similar to other reports using a single endocrine clinic cohort, our study was subject to selection bias and differential hormone testing. A complete endocrine evaluation was not performed in all patients and may have resulted in an underestimated prevalence of endocrinopathy. Ascertainment of hypopituitarism relied on clinical documentation, rather than systematic testing and standardized classification. For GHD, growth pattern data were not available for many of the patients, which affected confirmation of diagnosis in those on replacement therapy or with no anthropometrics prior to initiating therapy. MRI testing was performed at several institutions and imaging centers. Variability in the interpretation of MRI pituitary abnormalities between neuroradiologists may have led to an under or over-reporting of pituitary abnormalities.

\section{Conclusions}

Among children with $\mathrm{ONH}$, the prevalence of endocrinopathy is high including abnormalities in the HPG axis. Practitioners should be aware of the potential for precocious puberty throughout childhood and once patients reach a pubertal age, pubertal progression should be monitored annually. Evaluation of the HPG axis should be performed when patients fail to initiate puberty by an appropriate age (13 in females, 14 in males). Presence of micropenis, failure to progress through puberty normally, primary amenorrhea, or irregular menses would also warrant evaluation. Due to conflicting negative predictive values in evaluating MRI pituitary abnormalities in association with endocrinopathy, a normal pituitary gland on MRI should not exclude patients with $\mathrm{ONH}$ from an endocrine evaluation.

\section{Abbreviations}

ASP: Absence of the Septum Pellucidum; FSH: Follicle-stimulating Hormone; GH: Growth Hormone; GHD: Growth Hormone Deficiency; GnRH: Gonadotropin-releasing Hormone; HPG: Hypothalamic-pituitarygonadal; LH: Luteinizing Hormone; MRI: Magnetic Resonance Imaging; ONH: Optic Nerve Hypoplasia; T4: Thyroxine.

\section{Competing interests}

The authors declare that they have no competing interests.

\section{Authors' contributions}

OO was involved in the study concept and design, acquisition, analysis and interpretation of data, statistical analysis, drafting of the manuscript, and critical revision of the manuscript. DM and $\mathrm{MO}$ participated in the analysis and interpretation of data and critical revision of the manuscript. PG was involved in analysis and interpretation of data, statistical analysis, and critical revision of the manuscript. All authors read and approved the final manuscript.

\section{Acknowledgments}

The authors would like to thank Gabriel Shaibi PhD for assistance with analysis and interpretation of data and manuscript revision. The authors have no sources of funding to declare.

\section{Disclosures}

The authors have no sources of funding to declare. There are no prior publications or submissions with any overlapping information, including studies and patients. The manuscript has not been and will not be submitted to any other journal while it is under consideration by International Journal of Pediatric Endocrinology. The authors do not have any conflicts of interest to report. Each author has seen and approved the submission of the manuscript and takes full responsibility for the manuscript.

\section{Author details}

${ }^{1}$ Division of Pediatric Endocrinology and Diabetes, Phoenix Children's Hospital, 1919 E. Thomas Road, Phoenix, AZ 85016, USA. ${ }^{2}$ The Vision Center, Children's Hospital Los Angeles, Los Angeles, CA, USA.

Received: 15 October 2014 Accepted: 28 January 2015

Published online: 15 April 2015

\section{References}

1. Borchert M. Reappraisal of the optic nerve hypoplasia syndrome J Neuroophthalmol. 2012;32:58-67.

2. Atapattu N, Ainsworth J, Willshaw H, Parulekar M, MacPherson L, Miller C, et al. Septo-optic dysplasia: antenatal risk factors and clinical features in a regional study. Horm Res Paediatr. 2012;78:81-7.

3. Signorini SG, Decio A, Fedeli C, Luparia A, Antonini M, Bertone C, et al. Septo-optic dysplasia in childhood: the neurological, cognitive and neuro-ophthalmological perspective. Dev Med Child Neurol. 2012;54:1018-24.

4. Tear Fahnehjelm K, Dahl S, Martin L, Ek U. Optic nerve hypoplasia in children and adolescents; prevalence, ocular characteristics and behavioural problems. Acta ophthalmologica. 2014;92:563-70.

5. Hatton D, Schwietz E, Boyer B, Rychwalski P. Babies Count: the nationa registry for children with visual impairments, birth to 3 years. J AAPOS 2007:11:351-5.

6. Phillips PH, Spear C, Brodsky MC. Magnetic resonance diagnosis of congenital hypopituitarism in children with optic nerve hypoplasia. J AAPOS. 2001;5:275-80.

7. Birkebaek N, Patel L, Wright N, Grigg J, Sinha S, Hall C, et al. Endocrine status in patients with optic nerve hypoplasia: relationship to midline central nervous system abnormalities and appearance of the hypothalamic-pituitary axis on magnetic resonance imaging. J Clin Endocrinol Metab. 2003;88:5281-6.

8. Garcia M, Ty E, Taban M, Rothner A, Rogers D, Traboulsi E. Systemic and ocular findings in 100 patients with optic nerve hypoplasia. J Child Neurol. 2006;21:949-56 
9. Haddad NG, Eugster EA. Hypopituitarism and neurodevelopmental abnormalities in relation to central nervous system structural defects in children with optic nerve hypoplasia. J Pediatr Endocrinol Metab. 2005;18:853-8.

10. Ahmad T, Garcia-Filion P, Borchert M, Kaufman F, Burkett L, Geffner M. Endocrinological and auxological abnormalities in young children with optic nerve hypoplasia: a prospective study. J Pediatr. 2006;148:78-84.

11. Garcia-Filion P, Epport K, Nelson M, Azen C, Geffner ME, Fink C, et al. Neuroradiographic, endocrinologic, and ophthalmic correlates of adverse developmental outcomes in children with optic nerve hypoplasia: a prospective study. Pediatrics. 2008;121:e653-9.

12. Vedin AM, Garcia-Filion P, Fink C, Borchert M, Geffner M. Serum prolactin concentrations in relation to hypopituitarism and obesity in children with optic nerve hypoplasia. Horm Res. 2012;77:277-80.

13. Ramakrishnaiah $\mathrm{RH}$, Shelton JB, Glasier CM, Phillips PH. Reliability of magnetic resonance imaging for the detection of hypopituitarism in children with optic nerve hypoplasia. Ophthalmology. 2014;121:387-91.

14. Ma NS, Fink C, Geffner ME, Borchert M. Evolving central hypothyroidism in children with optic nerve hypoplasia. J Pediatr Endocrinol Metab. 2010;23:53-8.

15. Brodsky MC, Conte FA, Taylor D, Hoyt CS, Mrak RE. Sudden death in septo-optic dysplasia. Report of 5 cases. Arch Ophthalmol. 1997;115:66-70.

16. Huseman C, Kelch R, Hopwood N, Zipf W. Sexual precocity associated with optic dysplasia and hypothalamic hypopituitarism. J Pediatr. 1978;92:748.

17. Hanna CE, Mandel SH, LaFranchi SH. Puberty in the syndrome of septo-optic dysplasia. Am J Dis Child. 1989;143:186-9.

18. Nanduri VR, Stanhope R. Why is the retention of gonadotrophin secretion common in children with panhypopituitarism due to septo-optic dysplasia? E J Endocrinol. 1999;140:48-50.

19. Stephen MD, Zage PE, Waguespack SG. Gonadotropin-dependent precocious puberty: neoplastic causes and endocrine considerations. Int J Pediatr Endocrinol. 2011;2010:184502.

20. Margalith D, Tze WJ, Jan JE. Congenital optic nerve hypoplasia with hypothalamic-pituitary dysplasia. A review of 16 cases. Am J Dis Child. 1985:139:361-6.

21. Siatkowski R, Sanchez J, Andrade R, Alvarez A. The clinical, neuroradiographic, and endocrinologic profile of patients with bilatera optic nerve hypoplasia. Ophthalmology. 1997;104:493-6.

22. Reidl S, Mullner-Eidenbock A, Prayer D, Bernert G, Frisch H. Auxological, ophthalmological, neurological and MRI findings in 25 Austrian patients with septo-optic dysplasia (SOD). Horm Res. 2002;58:16-9.

23. Mohney BG, Young RC, Diehl N. Incidence and associated endocrine and neurologic abnormalities of optic nerve hypoplasia. JAMA Ophthalmol. 2013;131:898-902

24. Taylor D. Optic nerve axons: life and death before birth. Eye. 2005:19:499-527.

25. Kota SK, Gayatri K, Jammula S, Meher LK, Kota SK, Krishna SV, et al. Fetal endocrinology. Indian J Endocrinol Metab. 2013;17:568-79.

26. Stevenson EL, Corella KM, Chung WC. Ontogenesis of gonadotropin-releasing hormone neurons: a model for hypothalamic neuroendocrine cell development. Front Endocrinol. 2013;4:89.

27. Yuen KC, Koltowska-Haggstrom M, Cook DM, Fox JL, Jonsson PJ, Geffner $M E$, et al. Clinical characteristics and effects of $\mathrm{GH}$ replacement therapy in adults with childhood-onset craniopharyngioma compared with those in adults with other causes of childhood-onset hypothalamic-pituitary dysfunction. Eur J Endocrinol. 2013;169:511-9.

28. Borchert M, Garcia-Filion P, Fink C, Geffner M, Nelson M. Re: Ramakrishnaiah et al.: Reliability of magnetic resonance imaging for the detection of hypopituitarism in children with optic nerve hypoplasia (Ophthalmology 2014;121:387-91). Ophthalmology. 2014;121:e26-7.

\section{Submit your next manuscript to BioMed Central and take full advantage of:}

- Convenient online submission

- Thorough peer review

- No space constraints or color figure charges

- Immediate publication on acceptance

- Inclusion in PubMed, CAS, Scopus and Google Scholar

- Research which is freely available for redistribution

Submit your manuscript at www.biomedcentral.com/submit 